\title{
DA LUTA POR DIREITOS AO EMPODERAMENTO FEMININO: UMA DISCUSSÃO SOBRE OS ENTRAVES PARA O COMBATE À DESIGUALDADE DE GÊNERO NO BRASIL
}

\begin{abstract}
FROM THE STRUGGLE FOR RIGHTS TO WOMEN'S EMPOWERMENT: A DISCUSSION ON THE OBSTACLES TO THE FIGHT AGAINST GENDER INEQUALITY IN BRAZIL
\end{abstract}

\begin{abstract}
Resumo: O objetivo deste artigo é apresentar uma discussão sobre direitos das mulheres e empoderamento feminino, refletindo sobre os entraves para o combate à desigualdade de gênero na sociedade brasileira. Embora os avanços em relação a conquistas de direitos por parte das mulheres sejam importantes, este trabalho salienta que em contextos de avanço do pensamento conservador e a dificuldade em desmontar determinados elementos típicos da cultura e dos comportamentos discriminatórios e patriarcais são entraves que promovem a morosidade do combate à desigualdade de gênero no Brasil. Teoricamente, o estudo baseia-se nas autoras feministas como Simone de Beauvoir, Judith Butler, Heleieth Saffioti, Srilatha Batliwala, entre outras. Do ponto de vista metodológico, este trabalho alicerçou-se em pesquisa bibliográfica, exploratória e documental.
\end{abstract}

Palavras-chave: Empoderamento feminino. Feminismo. Desigualdade de gênero.

\begin{abstract}
The purpose of this article is to present a discussion on women's rights and women's empowerment, reflecting on the obstacles to the fight against gender inequality in Brazilian society. Although advances in the achievement of women's rights are important, this study emphasizes that in contexts of advancement of conservative thinking and the difficulty in dismantling certain elements typical of culture and of discriminatory and patriarchal behaviors, ther are obstacles that promote morosity in the fight against gender inequality in Brazil. Theoretically, the

\footnotetext{
"Doutora em Ciências Sociais pela Universidade do Estado do Rio de Janeiro (2011). Professora Adjunta do Programa de Pós-Graduação em Humanidades, Culturas e Artes da Universidade do Grande Rio.

Mestrando do Programa Interdisciplinar em Humanidades, Culturas e Artes da Universidade do Grande Rio (PPGHCA - UNIGRANRIO).

Pós Doutora pelo Programa de Pós Graduação em História da Universidade do Estado do Rio de Janeiro. Doutora em Sociologia pelo Instituto Universitário de Pesquisas do Rio de Janeiro. Atua na UNIGRANRIO como docente no Curso de Graduação em História e no Programa de Pós Graduação em Humanidades, Culturas e Artes.
} 
study is based on the feminist authors Simone de Beauvoir, Judith Butler, Heleieth Saffioti, Srilatha Batliwala, among others. From a methodological point of view, this work was based on bibliographic, exploratory and documentary research.

Keywords: Women's Empowerment. Feminism. Gender inequality. 


\section{INTRODUÇÃO}

No limiar do século XXI, avanços e conquistas em relação à questão de gênero e das mulheres são visíveis. Entretanto, é igualmente observado a dificuldade em manter os direitos conquistados, especialmente em contextos de crise econômica e política. A proposta deste artigo é apresentar uma breve reflexão acerca dos processos de lutas por direitos e a questão do empoderamento feminino, perpassando pela discussão da problemática que envolve o combate à desigualdade de gênero no Brasil.

A metodologia abordada neste estudo foi definida nos seguintes critérios: pesquisa bibliográfica sobre feminismo, direitos humanos, empoderamento feminino; exploratória em relação ao levantamento de dados/informações sobre desigualdade de gênero no Brasil, situação das mulheres no mercado de trabalho, entre outros.

$\mathrm{O}$ artigo está divido em duas partes. Na primeira parte, "feminismo, luta política e direitos das mulheres: caminhos e descaminhos", buscou-se discutir historicamente a construção do feminismo e as lutas travadas na sociedade e nos espaços políticos na busca pelos direitos das mulheres. Na segunda parte, "ONU Mulheres e o empoderamento feminino: os impasses para a sociedade brasileira", apresentamos uma reflexão sobre os entraves em relação às questões de gênero no Brasil, enfatizando o papel da ONU Mulheres nesse processo.

\section{FEMINISMO, LUTA POLÍTICA E DIREITOS DAS MULHERES: CAMINHOS E DESCAMINHOS}

Por mais que para muitos pareça uma questão recente, a luta pelos direitos das mulheres no Brasil é muito antiga e conta com um passado rico e com algumas personagens interessantes, que lutaram por seus direitos. A primeira manifestação importante que temos com este objetivo é a publicação, em 1832, do livro "Direito das mulheres e injustiça dos homens", de autoria da potiguar Nísia Floresta, pseudônimo adotado por Dionísia Gonçalves Pinto.

O trabalho de Nísia Floresta inaugura as obras feministas do Brasil e na América Latina, visto não existirem registros de outros anteriores ao dela em todo 
nosso continente. A autora se destaca ainda por tratar indagar quais as motivações para a ausência de mulheres exercendo determinadas funções, principalmente as que são cargos de comando, como generais, ministros e outras chefias (DUARTE, 2010, p. 14)

O livro seria, segundo a própria autora, uma tradução livre e comentada do livro da autora britânica Mary Wollstonecraft "A VindicationoftheRightofwoman" (Uma reinvindicação dos direitos das mulheres), publicado em 1792, tratando de questões referentes às desigualdades entre homens e mulheres impostas pela sociedade no campo das ciências, principalmente no que tange a capacidade intelectual das mulheres.

É interessante observarmos que a pesquisadora Maria Lúcia Garcia Pallares Burke (1996), apurou informações que dão conta que o livro de Nísia, apesar do que a própria narrava, seria na verdade a tradução de um livro de Mary WortleyMontagu (1689-1762), chamado "Womannot inferior toman" (As mulheres não são inferiores aos homens), que em contrapartida seria livremente inspirado no livro de François Poulan de La Barre, publicado em 1673 na França, intitulado "De l'egalitédesdeuxsexes" (A igualdade dos dois sexos). (CAMPOI, 2011, p. 198)

A contestação do lugar determinado para as mulheres na sociedade e a sua naturalização perpassa todo o trabalho da autora, que não deixa de apontar qual é a sua visão acerca daquilo que parece ser o olhar geral dos homens que compunham a sociedade brasileira:

Se cada homem, em particular, fosse obrigado a declarar o que sente a respeito de nosso sexo, encontraríamos todos de acordo em dizer que nós nascemos para seu uso, que não somos próprias senão para procriar e nutrir nossos filhos na infância, reger uma casa, servir, obedecer, e aprazer a nossos amos, isto é, a eles homens. (FLORESTA apud DUARTE, 2010, p. 81)

Esta concepção dos homens com relação as mulheres, tão bem construída por Nísia Floresta, é refutada posteriormente por ela de forma contundente. A autora destaca em sua obra que estas funções, tidas como de segundo grau, eram exclusivamente atribuídas as mulheres devido aos homens das sociedades patriarcais acreditarem ser menor a capacidade intelectual das mesmas. A autora 
mostra que isto era um reflexo direto da falta de oportunidades acadêmicas impostas às mulheres, como podemos observar no trecho a seguir:

\begin{abstract}
Para reconhecer, pois, se as mulheres são menos capazes que os homens para as ciências, é preciso atentar qual é o princípio que conduz a esse conhecimento; se ele não existe nas mulheres, ou se existe num grau menos perfeito, não se faz necessário mais provas para demonstrar que os homens têm razão. Porém, se ele é perfeito em um como em outro sexo, então se deve supor os homens invejosos e pode-se dizer, sem temeridade, que a única razão porque nos fecham o caminho às ciências é temerem que nós as levemos a maior perfeição que eles. Todos sabem que a diferença dos sexos só é relativa ao corpo e não existe mais que nas partes propagadoras da espécie humana; porém, a alma que não concorre senão por sua união com o corpo, obra em tudo da mesma maneira sem atenção ao sexo. Nenhuma diferença existe entre a alma de um tolo e de um homem de espírito, ou de um ignorante e de um sábio, ou a de um menino de 4 anos e um homem de 40 . Ora, como esta diferença não é maior entre as almas dos homens e das mulheres, não se pode dizer que o corpo constitui alguma diferença real nas almas. Toda sua diferença, pois, vem da educação, do exercício e da impressão dos objetos externos, que nos cercam nas diversas circunstâncias da vida. (FLORESTA apud DUARTE, 2010, p. 90)
\end{abstract}

A autora é pontual ao estabelecer que além das diferenças externas entre os dois sexos, nenhuma outra questão natural os diferenciam e, muito menos, tornam um grupo menos capaz que o outro de exercer. Segundo ela, se não há diferença entre as "almas" de um sábio e um ignorante, não é coerente acreditar que exista uma diferença entre homens e mulheres. E pontua, de forma muito feliz, que talvez o que mova os homens que acreditam e propagam a lógica patriarcal seja o temor em as mulheres desempenharem as mesmas funções que os homens de forma muito superior a eles. "Porque a ciência nos é inútil? Porque somos excluídas dos cargos públicos; e porque somos excluídas dos cargos públicos? Porque não temos ciência." (FLORESTA apud DUARTE, 2010, p. 82)

Em seguida, os movimentos pelos direitos das mulheres ganharam força, entre a metade final do século $X I X$ e o início do século $X X$, tendo como maior objetivo a luta pelo direito ao voto, dando ao movimento feminista uma característica mais forte de luta política. O movimento sufragista marcou este período em todo o mundo, no que foi denominada a primeira onda feminista, como podemos ver no trecho a seguir: 
Da metade do século XIX até as primeiras décadas do século $X X$, o sufragismo foi a face pública das reivindicações feministas. $O$ acesso à franquia eleitoral representava reconhecimento, pela sociedade e pelo Estado, de que as mulheres tinham condições iguais às dos homens para geriar a vida coletiva e também que elas possuíam visões do mundo e interesses próprios, irredutíveis aos de seus familiares. Afinal, um dos argumentos centrais para a exclusão política delas era que seus interesses já seriam protegidos pelo voto dos maridos ou do pais. (MIGUEL; BIROLLI, 2014, p. 93)

Desta forma podemos notar como a necessidade de as mulheres possuírem representatividade política pelo voto foi, durante muito tempo, a luta mais relevante para os movimentos femininos. Se acreditava que apenas através do voto, e da possibilidade de terem representantes que compreendessem suas necessidades, as mulheres teriam seus direitos reconhecidos e respeitados.

No Brasil a luta pela conquista do voto feminino se arrastou durante muito tempo, tendo começado por volta de 1891, quando foi elaborada e promulgada a primeira Constituição da República. Porém, as mulheres só vieram a ter o direito a voto reconhecido em 1932 através de um decreto que foi consolidado na Constituição Federal de 1934.

Nesta luta se destacaram algumas mulheres como Bertha Lutz, leolinda Daltro e Josefina Álvarez de Azevedo, por exemplo. Josefina, já em abril de 1890, defendia no jornal "A Família" que não podiam negar às mulheres, de forma impune, um dos mais sagrados direitos individuais. Reivindicava, além do direito ao voto, direitos civis e o direito ao divórcio. (SOIHET, 2006) A luta perpetrada por estas mulheres era extremamente difícil, devemos destacar, diante de todos os dogmas e limites estabelecidos ao gênero feminino por diversas instâncias, como a Igreja por exemplo.

A professora Leolinda Daltro foi a primeira mulher a reivindicar sua inscrição como eleitora, após a constituição de 1891, que previa o direito ao voto ao "cidadão brasileiros", o que deu margem para inúmeras discussões sobre a abrangência do termo às mulheres. Com base nisso, Leolinda pleiteou sua inscrição, que foi negada. Em 1910 ela funda o Partido Republicano Feminino, com o objetivo de levar novamente ao congresso a discussão sobre o voto feminino. Em 1917 organiza uma passeata de mulheres no Rio de Janeiro, o que pode ter sido primordial para a 
apresentação de um projeto de lei sobre o voto feminino através do Deputado Maurício de Lacerda. Infelizmente o projeto seques foi discutido na casa legislativa. (SOIHET, 2006)

Bertha Lutz, segunda mulher a integrar o funcionalismo público no Brasil, em 1918, lutou durante muito tempo pela aquisição de direitos por parte das mulheres, não só do direito ao voto, mas também o direito a uma melhor instrução, dentre outros. Sua luta se iniciou em 1918, quando enviou uma carta a uma revista fazendo uma severa crítica aos homens pelo tratamento que os mesmos dispensavam às mulheres, que as infantilizavam com a desculpa de as estarem protegendo. Em 1919 Bertha Lutz funda, juntamente a outras mulheres, a Liga para a Emancipação Intelectual da Mulher, que visava reconhecer os direitos da mulher e a sua participação na vida pública. Durante alguns anos Bertha Lutz organizou mulheres em torno das causas referentes a conquista de seus direitos.

Em 1932, BerthaLutz participou da comissão para elaboração do anteprojeto da constituição de 1934. No mesmo ano foi eleita suplente de Deputado Federal, assumindo a vaga em 1936 após o falecimento do titular da vaga, durante sua legislatura, ela defendeu outros direitos referentes às mulheres, como por exemplo o trabalho feminino. Com o golpe de 1937 e com o fechamento do congresso, Bertha Lutz passa a figurar somente em sua carreira como servidora pública. $\mathrm{E}$ o direito ao voto conquistado fica em suspenso, diante do regime instaurado por Getúlio Vargas.

Na década de 1950, com o reestabelecimento da democracia, as advogadas Romy Martins Medeiros da Fonseca e Orminda Ribeiro Bastos se destacam na luta pelos direitos das mulheres. Romy solicita à Câmara dos Deputados um estudo sobre a condição das mulheres casadas no Código Civil Brasileiro, onde vigorava a submissão destas mulheres aos seus maridos e que comparava as mesmas aos "silvícolas".

Com base no estudo Romy e Orminda elaboram uma proposta para um novo estatuto jurídico para a mulher casada, apresentado ao Congresso em 1951. O projeto tramitou durante mais de 10 anos no Congresso, sendo aprovado pelo mesmo e sancionado pelo presidente João Goulart em 1962. Com isso terminou, por exemplo, a exigência da autorização do marido para que as mulheres pudessem trabalhar fora, viajar, receber heranças, etc. 
A década de 1960 foi marcada pela liberação sexual, o advento da pílula e os movimentos dos direitos civis. O pensamento de Simone de Beauvoir, apresentado em seu livro "Segundo Sexo", publicado originalmente em 1948, ganhou o mundo e potencializou as discussões acerca das questões de gênero. Apesar de logo no início da década de 1960 o Brasil ter mergulhado em uma ditadura militar, as reflexões de Beauvoir causaram impacto em pensadoras daqui, como podemos ver neste relato de HeleiethSaffioti (1999):

Li O Segundo Sexo em 1962, quando comecei a pesquisar a temática da mulher. Embora estivesse estudando professoras primárias e operárias têxteis em Araraquara, problemática bem localizada, fiquei fascinada com o livro. A literatura a respeito do tema era tão restrita e, algumas vezes, incidia sobre universos empíricos tão acanhados, que o livro em pauta sobressaía. Era realçado também pela coragem da autora de focalizar temas tabus. Isto significava, na década de 1960, o desvelamento de dimensões da vida escondidas pelos poderosos. Assim, o livro tinha também o sabor do proibido. Não procurei averiguar, na parca bibliografia então existente, a justeza dos fatos históricos analisados. Para meu pequeno conhecimento de tudo, O Segundo Sexo constituía um manancial de saberes. (SAFFIOTI, 1999, p. 161).

O estudo de Beauvoir se consolida como a principal fonte para a luta das mulheres, na chamada segunda onda feminista, que encontrou apoio também em outras escritoras, principalmente americanas como Kate Millet e Betty Friedan. O entendimento era de que não bastava somente o reconhecimento de direitos para as mulheres, mas também se fazia necessário o entendimento de que ambos os gêneros mereciam direitos iguais, com suas peculiaridades e diferenças sendo valorizadas. Além disso, a segunda onda feminista é marcada pelo reconhecimento da necessidade de serem realizadas pesquisas que objetivassem estudar as questões ligadas as mulheres.

A terceira onda feminista surge, de acordo com Bonnici (2007), a partir da década de 1990. Ela teria suas bases fundamentadas nos fatos políticos e sociais que ocorreram a partir da segunda metade da década de 1980, como a crise da União Soviética e o fim das ditaduras latino-americanas. Esta terceira onda tem um conteúdo mais amplo de direitos a serem reivindicados, considerando lutas 
específicas como os direitos das mulheres negras, a teoria queer, o póscolonialismo, a teoria crítica, etc.

Dentre estas teorias, optamos por destacar aqui a teoria queer, apresentada pela filósofa americana Judith Butler (2016), que proporciona a possibilidade de se contestar os padrões daquilo que é considerado adequado ou não para este ou aquele sexo biológico e, também, para a forma como se relacionam com sua sexualidade e seu gênero diante da sociedade. Butler (2016) busca desconstruir as ideias de gênero encontradas em nossa sociedade, mostrando que se trata de um constructo social, como podemos ver no trecho a seguir:

O gênero não deve ser meramente concebido como a inscrição cultural de significado num sexo previamente dado (uma concepção jurídica); tem de designar também o aparato mesmo de produção mediante o qual os próprios sexos são estabelecidos. Resulta daí que o gênero não está para a cultura como o sexo está para a "natureza sexuada" ou o "sexo natural" é produzido e estabelecido como "pré-discursivo", anterior à cultura, uma superfície politicamente neutra sobre a qual age a cultura. (BUTLER, 2016, p. 27).

Atualmente vivenciamos um momento onde os desdobramentos da terceira onda do feminismo seguem sendo debatidos. Hoje podemos encontrar como uma manifestação legítima da luta das mulheres a questão do Empoderamento Feminino. O tema é extremamente debatido não só por autoras, mas também pela sociedade, e além disso é refletido nas atitudes e discursos de diversas personalidades.

De acordo com SrilathaBatliwala (1997), o empoderamento é um processo que tem como foco a modificação de questões sistêmicas que marginalizam e colocam em posição de desvantagem quaisquer grupos perante a sociedade. A autora frisa que o termo engloba a palavra "poder", e esta seria a sua característica mais marcante. Sendo assim, devemos considerar o que ela explica neste sentido:

(...) o controle sobre bens materiais, recursos intelectuais e a ideologia. Os bens materiais sobre os quais o controle pode ser exercido podem ser físicos, humanos ou financeiros, como a terra, a água, as florestas, os corpos de pessoas, o trabalho, o dinheiro e o acesso a ele. Os recursos intelectuais incluem conhecimento, informação e idéias. Controle sobre ideologia significa a capacidade de gerar, propagar, sustentar e institucionalizar conjuntos específicos de crenças, valores, atitudes e comportamentos, praticamente 
determinando a maneira pela qual as pessoas percebem e funcionam em um dado ambiente socioeconômico e político. (BATLIWALA, 1997, p. 191-192, tradução nossa) ${ }^{i}$

Com relação ao empoderamento feminino, devemos considerar como o termo é conceituado pela autora brasileira Cecília Sardenberg (2012):

Para nós, feministas, o empoderamento de mulheres, é o processo da conquista da autonomia, da auto-determinanação. E trata-se, para nós, ao mesmo tempo, de um instrumento/meio e um fim em si próprio. O empoderamento das mulheres implica, para nós, na libertação das mulheres das amarras da opressão de gênero, da opressão patriarcal. Para as feministas latino americanas, em especial, o objetivo maior do empoderamento das mulheres é questionar, desestabilizar e, por fim, acabar com o a ordem patriarcal que sustenta a opressão de gênero. (SARDENBERG, 2012, p. 2).

Para Cecília o empoderamento feminino é um caminho para o fim da dominação masculina e das violências a que as mulheres são submetidas constantemente através das relações de gênero. Esta é a luta presente no cotidiano das mulheres brasileiras, que têm de se desvencilhar dos problemas que enfrentam cotidianamente diante da cultura patriarcal em que estamos inseridos.

Neste sentido, no campo dos direitos humanos, a questão do empoderamento feminino tornou-se uma questão importante nos espaços dedicado às causas femininas pela Organização das Nações Unidas, conforme veremos a seguir.

\section{A ONU MULHERES E O EMPODERAMENTO FEMININO: OS IMPASSES PARA A SOCIEDADE BRASILEIRA}

Em 1979, na Assembleia Geral da Organização das Nações Unidas, a questão da discriminação contra a mulher foi um tema recorrente. Nesta Assembleia foi incorporada os pressupostos elaborados pela Convenção para a eliminação de

\footnotetext{
'Original do Espanhol: elcontrol sobre losbienesmateriales, los recursos intelectuales y laideología. Los bienesmateriales sobre loscualespuedeejercerseelcontrolpueden ser físicos, humanos o financieros, tales como latierra, el agua, los bosques, loscuerpos de las personas, eltrabajo, eldinero y elacceso a éste. Los recursos intelectualesincluyenlosconocimientos, lainformación y lasideas. El control sobre laideología significa lahabilidad para generar, propagar, sostener e institucionalizar conjuntos específicos de creencias, valores, actitudes y comportamientos, determinando virtualmente la forma en que las personas perciben y funcionanenun entorno socioeconómico y político dado.
} 
todas as formas de discriminação contra a mulher. O primeiro artigo instituído por esta convenção constituiu um passo fundamental para as questões que envolvem o combate à discriminação e o empoderamento feminino:

"Discriminação contra a mulher" significará toda distinção, exclusão ou restrição baseada no sexo e que tenha por objeto ou resultado prejudicar ou anular o reconhecimento, gozo ou exercício pela mulher, independentemente de seu estado civil, com base na igualdade do homem e da mulher, dos direitos humanos e liberdades fundamentais nos campos político, econômico, social, cultural e civil ou em qualquer outro campo.i

Das últimas décadas do século $\mathrm{XX}$ em diante é inegável os avanços em torno da conquista de direitos por parte das mulheres, criação de espaços estatais para promoção de igualdade de gênero, bem como políticas públicas com esta finalidade e de combate à discriminação. Entretanto, conforme salientou Angela Maria Carneiro Araújo e Regina Facchini (2018),

No entanto, a Declaração dos Direitos Humanos completa 70 anos em um contexto internacional em que ocorre uma crescente hostilidade contra os direitos humanos e aumentam as manifestações de ódio, de intolerância e de rejeição aos direitos conquistados pelas mulheres, pelas populações negra, indígena e LGBTI, entre outros grupos e comunidades.

Esta constatação, salienta o quanto a manutenção das conquistas de direitos por parte das "minorias" sofre ataques para em contextos de crises econômicas, políticas e sociais.

É fato que os movimentos feministas delegaram uma série de conquistas. No mundo do trabalho, conforme chamou a atençãoMarilane Teixeira (2014), o número de mulheres com nível superior dobrou de acordo com o senso de 2010, e, portanto, nos primeiros anos do século XXI, ultrapassaram os homens em carreiras de alta remuneração, como Arquitetura, Medicina, Direito, entre outras. A inserção no mercado de trabalho também é evidente e positiva: participação nos espaços legislativos, criação de órgãos para gerir políticas públicas para mulheres,

\footnotetext{
iirtigo $1^{\circ}$. Da Convenção para a eliminação de todas as formas de discriminação contra a Mulher, 1979.
} 
institucionalização de Leis de combate de violência contra as mulheres (Lei Maria da Penha e do Feminicídio).

Entretanto, apesar das conquistas, as desigualdades e violências de gênero permanecem no bojo da sociedade brasileira. Em 2016 foi publicado o Relatório de Desenvolvimento Humano do Programa das Nações Unidas para o Desenvolvimento (PNUD) e, neste documento constatou-se a seguinte realidade no Brasil: as mulheres ainda recebem até $25 \%$ a menos do que homens em atividades de trabalho semelhantes; apenas 10\% de mulheres ocupam cadeiras legislativas.

Quando atrelados às dimensões de raça e etnia, os dados em relação às mulheres e o mercado de trabalho são ainda mais discrepantes. O "passado" escravocrata reflete-se em algumas dimensões, entre as quais o trabalho doméstico é uma das marcas mais vivas. De acordo com estudo elaborado pelo Instituto de Pesquisa Econômica Aplicada (Ipea) juntamente com a ONU Mulheres, os dados históricos sobre o trabalho doméstico no Brasil (a partir dos critérios de raça, sexo, gênero) demonstram a desigualdade. A série histórica retrata 20 anos de trabalho doméstico (1995 a 2015) e denota que a maioria dos trabalhadores domésticos são mulheres, negras e pardas. Em 1995 havia um total de 4.764 .840 da população feminina ocupada em trabalho doméstico e, em 2015 aumentou para 5.755.600. Deste total, as mulheres brancas somavam: 2.104.297 (em 1995) e 2.008.289 (em 2015) e as mulheres negras, 2.660 .543 (em 1995) e 3.747.311 (em 2015). Portanto, enquanto o número de trabalhadoras domésticas brancas diminuiu, o de mulheres negras aumentou consideravelmente, ao longo de vinte anos.ii

Em relação à violência contra as mulheres, a situação é alarmante, tendo apresentado crescimento significativo e constante desde a década de 1980. De acordo com Waiselfisz (2015), a partir dos dados do Sistema Único de Saúde (SUS), os atendimentos às mulheres vítimas de violência física, sexual e psicológica atingem uma média de 405 casos por dia. As mortes (tipificadas por feminicídio) aumentaram ao entre 1980 e 2013 de 2,3 para 4,8 por 100.000 mil/habitantes. O Conselho Nacional de Justiça (CNJ) publicou, em 2018, o Relatório "O Poder

\footnotetext{
iii Os dados completos desta pesquisa estão disponíveis no Relatório do IPEA "Retratos das Desigualdades de Gênero e de Raça", disponível em: http://www.ipea.gov.br/retrato/indicadores trabalho domestico remunerado.html
} 
Judiciário na Aplicação da Lei Maria da Penha", demonstrando que, apensar dos esforços do poder judiciário, somente em 2017, quase um milhão de casos de violência doméstica contra as mulheres estavam pendentes.

Outra questão preocupante, no campo político, é a ação de bancadas conservadoras no legislativo brasileiro que corroboram para o retrocesso em relação há alguns direitos conquistados pelos movimentos feministas. De acordo com Araújo e Facchini (2018),

\begin{abstract}
Em contraste com a maior visibilidade e difusão dos feminismos e das mudanças nas convenções acerca do que pode ser classificado como violência, a virada da última década é marcada por preocupante reação conservadora. Em uma legislatura apontada como uma das mais conservadoras das últimas décadas, é produzido um conjunto de propostas legislativas que retrocedem direitos, como no caso do PL 5069/2013, que altera e restringe a abrangência do atendimento a mulheres vítimas de violência sexual em hospitais, pela exigência da apresentação de boletim de ocorrência e exame de corpo de delito para a prevenção ou interrupção da gravidez decorrente de estupro, ou dos vários projetos de lei que visam a proteção da vida desde a concepção em qualquer caso.
\end{abstract}

Entretanto, é importante salientar que, do ponto de vista dos direitos humanos, a ONU tem se dedicado a questão das mulheres, especificamente através da institucionalização da ONU Mulheres. Criada em 2010, a Entidade das Nações Unidas para a Igualdade de Gênero e o Empoderamento das Mulheres (ONU Mulheres), tem como principal objetivo o direito de mulheres e meninas terem uma vida livre de discriminação, violência e pobreza e, também, defende a igualdade de gênero como um dos principais elementos para o alcance do desenvolvimento. Esta entidade defende e enfatiza a participação das mulheres em todos os campos da vida e destaca cinco áreas prioritárias: aumento da liderança e participação das mulheres; eliminação da violência contra mulheres e meninas; engajamento das mulheres em todos os processos de paz e segurança; aprimoramento do empoderamento econômico das mulheres; inserir e garantir a igualdade de gênero no centro do planejamento e dos orçamentos de desenvolvimento nacional. ${ }^{\text {iv }}$

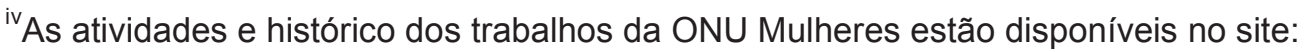
https://nacoesunidas.org/agencia/onumulheres/
} 
O empoderamento feminino é um termo relativamente novo. De acordo com a ONU Mulheres, empoderamento pode ser conceituado da seguinte forma:

\begin{abstract}
Dar ou adquirir poder ou mais poder. O empoderamento significa uma ampliação da liberdade de escolher e agir, ou seja, o aumento da autoridade e do poder dos indivíduos sobre os recursos e decisões que afetam suas próprias vidas. A pessoa empoderada pode definir os seus objetivos, adquirir competências (ou ter as suas próprias competências e conhecimentos reconhecidos), resolver problemas e desenvolver seu próprio sustento. É, simultaneamente, um processo e um resultado. Fala-se, então, do empoderamento das pessoas em situação de pobreza, das mulheres, dos negros, dos indígenas e de todos aqueles que vivem em relações de subordinação ou são desprivilegiados socialmente. (ONU MULHERES, 2016, p. 21).
\end{abstract}

Neste sentido, em se tratando do empoderamento das mulheres, o poder de delegar sobre todas as instancias de suas vidas é essencial. No que diz respeito ao mundo trabalho, por exemplo, a inequidade salarial provocada pela desigualdade de gênero é um entrave para que as mulheres conquistem independência econômica. Em determinadas situações, esta realidade pode significar aumento de violência de gênero, cuja dependência econômica em relação ao outro inibe o direito de escolhas e de ir e vir da mulher. Ainda nos espaços de trabalho, embora as mulheres tenham níveis altos de escolaridade e, por conseguinte formação adequada para o exercício de altos cargos, a discriminação também é um entrave. Portanto, os aspectos culturais de subjugação feminina, discriminação social e abusos de poder que alocam as mulheres em condição humilhante, formam um conjunto de questões a serem combatidas.

\title{
4 CONSIDERAÇÕES FINAIS
}

Apresentamos neste artigo uma discussão sobre feminismo, empoderamento, a luta por igualdade de gênero e a questão dos direitos humanos no Brasil. Na primeira parte discutimos, historicamente, o processo de lutas feministas, chamando a atenção para as reflexões em torno do empoderamento na atualidade. 
Na segunda parte, chamamos a atenção para as conquistas feministas no Brasil e, por outro lado, abordamos a dificuldade de manutenção de tais conquistas. O mercado de trabalho, a igualdade entre os gêneros e o combate a toda forma de violência contra as mulheres, são lutas feministas que, embora apresentem êxito em alguns aspectos, a chamada onda conservadora do ponto de vista político é um dos entraves para a manutenção dos direitos adquiridos.

\section{REFERÊNCIAS}

ARAÚJO, Angela Maria Carneiro; FACCHINI, Regina. Mulheres e direitos humanos no Brasil: avanços e desafios. Jornal da UNICAMP, 12 mar. 2018. Disponível em: https://www.unicamp.br/unicamp/ju/artigos/angela-maria-carneiro-araujo/mulheres-edireitos-humanos-no-brasil-avancos-e-desafios. Acesso em: 10 dez. 2018.

BATLIWALA, S. El significado delempoderamiento de lasmujeres: nuevos conceptos desde laacción. En Magdalena León, Poder y empoderamiento de lasmujeres. Santa Fé: T/M Editores, 1997.

BEAUVOIR, Simone de. O segundo sexo: fatos e mitos: volume I. Tradução: Sérgio Milliet. 3. ed. Rio de Janeiro. Nova Fronteira, 2016.

BEAUVOIR Simone de. O segundo sexo: a experiência vivida: volume II. Tradução: Sérgio Milliet. 3. ed. Rio de Janeiro. Nova Fronteira, 2016.

$\mathrm{BONNICI}$, Thomas. Teoria e crítica literária feminista: conceitos e tendências.Maringá: Eduem, 2007.

BRASIL. Conselho Nacional de Justiça. O Poder Judiciário na aplicação da Lei Maria da Penha: 2018. Disponível

em: http://www.cnj.jus.br/files/publicacoes/arquivo/5f271e3f54a853da92749ed051cf3 059_18ead26dd2ab9cb18f8cb59165b61f27.pdf. Acesso em: 10 dez. 2018.

BUTLER, Judith P.Problemas de gênero: feminismo e subversão da identidade. 11. ed. Tradução: Renato Aguiar. Rio de Janeiro: Civilização Brasileira, 2016.

CAMPOI, Isabela Candeloro. O livro "Direitos das mulheres e injustiça dos homens" de Nísia Floresta: literatura, mulheres e o Brasil do século XIX. História, São Paulo, v. 30, n. 2, p. 196-213, 2011.

DUARTE, Constância Lima. Nísia Floresta. Fundação Joaquim Nabuco, 2010.

GÓIS, Joao Bosco Hora. Romy Martins Medeiros da Fonseca (1921-2013). Revista Gênero, v. 14, n. 1, 2016. 
MIGUEL, Luis Felipe; BIROLI, Flávia. Feminismo e política: uma introdução. São Paulo: Boitempo, 2014.

ONU MULHERES. Princípios de empoderamento das mulheres. 2016. Disponível em: http://www.onumulheres.org.br/wpcontent/uploads/2016/04/cartilha_WEPs_2016.pdf. Acesso em: 10 dez. 2018.

SAFFIOTI,Heleieth. Primórdios do conceito de gênero. Cadernos Pagu, [S.I.], v. 12, p. 157-163, 1999.

SARDENBERG, Cecília Maria Bacellar. Conceituando "Empoderamento" na perspectiva feminista. 2012.

SOIHET, Rachel. A pedagogia da conquista do espaço público pelas mulheres ea militância feminista de Bertha Lutz. 2006.

TEIXEIRA, Marilane O. Os avanços e continuidades para as mulheres no mundo do trabalho entre 2004 e 2014. [2014]. Disponível em:

http://promotoraslegaispopulares.org.br/os-avancos-e-continuidades-para-asmulheres-no-mundo-do-trabalho-entre-2004-e-2014/. Acesso em: 10 dez. 2018.

WAISELFISZ, JulioJacobo. Mapa da Violência 2015: homicídio de mulheres no Brasil. Rio de Janeiro: FLACSO Brasil, 2015. Disponível em:

https://www.mapadaviolencia.org.br/pdf2015/MapaViolencia_2015_mulheres.pdf. Acesso em: 10 dez. 2018. 